\title{
NOTAS
}

\section{"Instrucciones para Matar Hormigas en Roma', o la Dinámica de la Palabra}

A poem should not mean But be.

Archibald MacLeish

Como otros capitulos en Historias de cronopios y de famas, "' "Instrucciones para matar hormigas en Roma" puede parecer, tras la primera lectura, un texto desconcertante, provocativo y agresivo como una broma, sin más objeto que la pura satisfacción del autor al escribirlo. El propósito de estas notas es sugerir un posible enfoque crítico que no quite validez a esos párrafos.

Sabemos, por lo pronto, que no se trata de un cuento, por cuanto estas dos breves páginas no narran absolutamente nada que se proponga como ya ocurrido (no hay verbos en pretérito ni en imperfecto); sugieren, en cambio, una acción hipotética por medio de futuros (a modo de profecía) y de infinitivos (con lo que la acción queda en su pura esencia y fuera del tiempo). Pero entonces, ¿cómo entender el texto? ¿qué sentido secreto lo explica? ¿qué hermética semántica se oculta en las hormigas, en las fuentes, en los mapas? ¿Por qué las lamias y el lémur? El monólogo está incluido en la primera parte del libro-" "Manual de instrucciones" - en las primeras líneas del cual se denigra "la satisfacción perruna de que todo esté en su sitio"' (p. 11). ¿Se trata acaso de la actividad mental de un cronopio que quiere deshacerse de los famas? Esto de " $m a t a r$ hormigas" nos recuerda un poco al "muera el perro" del manicomio de Rayuela ${ }^{2}$ : terminar con los reglamentos inicuos y las opresiones paralizantes. En ese caso, "mataremos las hormigas que codician las fuentes" podría traducirse "destruiremos lo gregario, lo mecánico, lo pavloviano en nosotros que impide nuestra libertad"'. Imposible olvidar que las hormigas reaparecen en Libro de $\mathrm{Manuel}^{3}$ como imagen plasmadora de los mecanismos de represión

1 Julio Cortázar, Historias de cronopios y de famas (Buenos Aires: Ediciones Minotauro, 1969). Todas las citas se hacen por esta edición.

${ }^{2}$ Rayuela (Buenos Aires: Editorial Sudamericana, 1966). Todas las citas se hacen por esta edición.

${ }^{3}$ Libro de Manuel (Buenos Aires: Editorial Sudamericana, 1973). La exterminación de las hormigas aparece también en el cuento "Los venenos", en Final del juego (Buenos Aires: Editorial Sudamericana, 1972), pero no se relaciona, en absoluto, con el texto aquí analizado. 
más reaccionarios. En el párrafo final del monólogo se anuncia que "costará" saber dónde está el "centro" (¿el que buscaba Oliveira?). Ya conocemos el sentido de la actividad absurda per se (tan bien ilustrada en "Ocupaciones raras"): cuestionar cómicamente y por la locura nuestro inveterado, irrenunciable pragmatismo; poner al lector fuera de sitio, desquiciarlo. Entonces el texto cumple con la nueva estética: propone el acto gratuito o absurdo como afirmación de una libertad terriblemente coartada en estos tiempos. "Todo lo que nos pone fuera de nosotros, dice Octavio Paz, posee la misma virtud liberadora". ${ }^{4}$

No niego la posibilidad de este enfoque pues es inevitable que el texto proyecte un sentido y que el crítico procure explicarlo, pero lo cierto es que aquí la anécdota explícita ha desaparecido. No quiero decir con esto que sea inútil buscar un referente y conceptualizar lo que el hablante dice por medio de imágenes, pero creo que el que intente convertirse en exégeta de sus símbolos obtendrá menos que quien se acerque al texto atraído primero por lo que éste es: una estructura que se genera a sí misma gracias a una intensísima dinámica de la palabra. Tenga o no sentido lógico, es evidente que este apretado ramo de imágenes tiene sentido poético y que reúne las condiciones que reclama la poesía para ser.

Un paréntesis necesario. Recuérdese que, de los tres géneros poéticos, el único que admite lo externo no per se sino en cuanto contribuye a la re-creación de una vivencia intima es el lírico: "el mundo exterior, dice Aguiar, no significa para el lírico una objetividad válida en cuanto tal, pues sólo constituye un elemento de la creación lírica en la medida en que es absorbido por la interioridad del poeta y trasmudado (sic) en revelación intima', ${ }^{5}$ Por esto, quien por primera vez confronte el texto, debe despojarse del prejuicio narrativo que lo lleve a identificar con un relato todas las secuencias de Historias de cronopios y de famas. El que la imbricación de los géneros sea un fenómeno común reconocido por el mismo Cortázar ahorra más explicaciones sobre el caso pero también hace necesaria una aclaración: no se trata aquí de una forma híbrida épico-lírica (como "Uno de tantos días en Saignon") sino de una secuencia lírica en la que (como en "Tu más profunda piel" "6 ) se conjugan los rasgos de la poesía con (en menor grado) los de la prosa. Por ello es que propongo para estos párrafos una lectura poética.

Bachelard ha visto que para indagar "los problemas planteados por la imaginación poética" hay que abandonar "el racionalismo activo" y "llegar a una fenomenología de la imaginación", a una "metafísica de la imaginación" porque "la imagen es antes que el pensamiento" (es decir, es aprehendida o intuida por el autor y el lector antes que conceptualizada) y porque el poema se ha formado como "agrupación de imágenes". 7 Es cierto: todo poema se constituye como imagen; sólo que en este caso el ritmo es todavía anterior a la imagen. La puerta de entrada a esta secuencia se abre en el capitulo 82 de Rayuela:

¿Por qué escribo esto? No tengo ideas claras, ni siquiera tengo ideas. Hay jirones, impulsos, bloques, y todo busca una forma, entonces entra en juego el ritmo y yo escribo dentro de ese ritmo, escribo por él, movido por él y no por eso que llaman

${ }^{4}$ Cf. Octavio Paz, El arco y la lira (México: Fondo de Cultura Económica, 1970), p. 52.

${ }^{5}$ Vitor Manuel de Aguiar e Silva, Teoria de la literatura (Madrid: Gredos, 1972), p. 181.

${ }^{6}$ Estos dos textos se encuentran en Ultimo round (México: Siglo XXI Editores,1969), pp.15-26 y pp.93- 96.

${ }^{7}$ Gaston Bachelard, La poética del espacio (México: Fondo de Cultura Económica, 1965), pp. 9, 11 y 17. 
el pensamiento y que hace la prosa, literaria u otra. Hay primero una situación confusa, que sólo puede definirse en la palabra; de esa penumbra parto, y si lo que quiero decir (si lo que quiere decirse) tiene suficiente fuerza, inmediatamente se inicia el swing, un balanceo rítmico que me saca a la superficie, lo ilumina todo, conjuga esa materia confusa y el que la padece en una tercera instancia clara y como fatal: la frase, el párrafo, la página, el capitulo, el libro (p. 458).

No se vea en esta alusión al origen del texto un intento de recurrir a la "falacia intencional ", tan desacreditada por Wimsatt y Bachelard. ${ }^{8}$ Indagar qué pensaba Cortázar al escribir el monólogo, de dónde, de qué pequeño hecho de su vida surgió la imagen de matar hormigas en Roma, no es un atajo sino una vía cerrada. No trato aquí de demostrar cómo surgió el texto en la mente del autor sino cómo, cada vez que lo leo, el texto se genera a sí mismo a partir de una onda sonora; cómo cada palabra va llamando a la siguiente porque el juego de fonemas y acentos ("el balanceo") la reclama; cómo la secuencia, que es sobre todo una elaboración rítmica, atiende primero al valor fónico (sine qua non) de la frase y después a la visión que ésta conjura, de modo que el ritmo da vida y sentido a la imagen. ${ }^{9}$ Por eso, aunque el texto es muy rico en imágenes que se suceden en un desborde continuo, el elemento más significativo, el elemento estructurador, es el ritmo o, precisando más, la feliz alternación de los ritmos binarios y ternarios. Es, por consiguiente, una instancia poética sostenida por el ritmo, una visita fugaz de la poesía entre la delirante y juguetona seriedad del "Manual".

Antes de internarme en las andaduras rítmicas y los fraseos correspondientes, recordaré que la despersonalización del hablante (no se emplea la primera persona del singular ni una sola vez) es carácter distintivo de la lírica moderna. ${ }^{10}$ Para conseguirla se usan diferentes recursos: la tercera persona ("...es el menester..."), el infinitivo ("Y sin dormir seguirlas..."), las frases impersonales ("está dicho", " "hay que..."'), la voz pasiva con "se" ("se irá viendo...") y la primera persona del plural ("buscaremos...").

"Instrucciones para matar hormigas en Roma" se estructura en cinco párrafos. Tras el impulso adquirido en el primero, el segundo, más cerca del lenguaje cotidiano y no ajeno a los nexos del discurso ("lo cual", "pues") y a las expresiones puramente conceptuales ("estamos seguros de que..."), es un paréntesis en el que se ordenan lógicamente los primeros pasos de la actividad propuesta ("Primero...y ahora..."). El tercer párrafo, el más extenso y rico, consta de tres cláusulas con numerosas ramificaciones e interpolaciones en las que resuenan algunas formas métricas: se pueden contar algunos dactílicos bastante marcados y algunos pentasílabos y heptasílabos. La conclusión es un endecasílabo que

${ }^{8}$ Cf. William Wimsatt, The Verbal Icon (Lexington: University of Kentucky Press, 1954), pp. 3-18 y G. Bachelard (que la denomina "psicologismo"), op. cit., p. 22. Para la distinción entre "falacia intencional" y "falacia genética" véase José Miguel Ibáñez Langlois, La creación poética (Santiago, Chile: Editorial Universitaria, 1969), p. 30.

" "Ritmo, imagen y sentido se dan simultáneamente en una unidad indivisible", dice Octavio Paz (op, cit., p. 70) refiriéndose al modo de ser de la obra literaria. La anterioridad que aquí invocamos para el ritmo se refiere al orden en que estos tres elementos se imponen al lector.

${ }^{10}$ Cf. Hugo Friedrich, Estructura de la lirica moderna (Barcelona: Editorial Seix Barral, 1959), p. 49. "Interioridad neutral en lugar de sentimientos", dice Friedrich (p. 37). Cf. también "El yo artificial; la deshumanización", pp. 104-108. 
forma una cláusula ambigua ya que, por la puntuación, es independiente de la anterior en tanto que, por la sintaxis, es un elemento más de la misma. Rítmica e imaginativamente la segunda cláusula de este párrafo ("Y sin dormir...subter ráneos") es el momento climático del texto. La pausa que la sigue y la brevedad de la última frase indican un relajamiento de la tensión tras el esfuerzo del clímax. El cuarto párrafo, comparable en extensión al primero, al segundo y al quinto, desarrolla, entre aliteraciones y anáforas, un nuevo crescendo, especie de subclímax que alcanza un máximo de cinco miembros ("acercarse...der ramarse' '), y se cierra, suave pero bien definido, con un endecasílabo sáfico. El quinto, más breve y lleno de confiadas aseveraraciones, representa un descenso en el tono expresivo, aunque la anáfora de una frase ("mataremos las hormigas") pareciera sugerir por un instante un recomienzo de la intensidad. Esto no ocurre y la última frase es un anticlímax sonoramente aliterativo en el que se potencia la vocal media cerrada (/o/). La frase final consta de tres claras cláusulas rítmicas tetrasílabas.

El tema estilístico o recurso retórico fundamental de la secuencia es la plurimembración, de la que hay en total veinticuatro ejemplos: seis en el primer párrafo, cuatro en el segundo, nueve en el tercero, tres en el cuarto y dos en el quinto. Los grupos plurimembres-que dan lugar a varios casos de paralelismo, rima interior anáfora y aliteración-son los siguientes: Primer párrafo: 1) las aguas de las fuentes, las pizarras vivas, los camafeos temblorosos; 2) la historia, las dinastías, las conmemoraciones; 3) encontrar $(.$.$) organizar (\ldots) ; 4)$ de sangre crecida, de cornucopias erizadas $(.) ; 5$.$) se lime$ (...) se arrastre $(.$.$) ; 6) manso (...) sin fuerza (...) sin hormigas. Segundo párrafo: 1) en los$ mapas (...) en las plantas $(.) ;$.2 ) surtidores $(.$.$) cascadas (.) ;$.3 ) buscarlas (..) envolverlas $(\ldots)$; 4) que las tenemos (...) que conocemos (...). Tercer párrafo: 1) más difícil, más recogido; 2) recogido (...) silencioso; 3) horadar (...) entender (...) guardar (...); 4) de tanto susurro (...) de tanto gorgotear (..); 5) las direcciones, las confluencias, las otras calles, las vivas ; 6) seguirlas (...) andar (..) subir (...) correr (...) aterrar (..) extraer (...) no pedir (...); 7) con varas (...) con dos varillas (...) con una sola (...);8) de horqueta, de triángulo; 9) a los carabineros (...) a la población (...). Cuarto párrafo: 1) por placer de aguas, por artificio de juego; 2) acercarse (...) confluir (...) enlazarse (...) crecer (...) derramarse (...); 3) el tambor de vidrio líquido, la raíz de copas pálidas, el caballo profundo. Quinto párrafo: 1) mataremos las hormigas (...) calcinaremos las galerías (...) mataremos las hormigas $(.) ;$.2 ) con soldados $(. .$.$) con monjas.$

Como se ve, la mayor concentración de ejemplos y el grupo más numeroso y complejo (grupo 6 de siete términos) se dan en el momento de mayor tensión que representa la cima de la intensidad poética. En cada caso el número de grupos plurimembres y su complejidad estructural son directamente proporcionales a la extensión del párrafo y a la tensión que éste genera. El momento climático se manifiesta por medio del grupo de siete términos pero en su comienzo la tensión no alcanza a ascender, dispersa en las múltiples interpolaciones del primer elemento ("seguirlas, con varas de avellano en forma de horqueta, de triángulo, con dos varillas en cada mano, con una sola sostenida entre los dedos flojos, pero todo esto invisible a los carabineros y a la población amablemente recelosa" '); de modo que el crescendo se inicia recién con los términos segundo ("andar...") y tercero ("subir..."). El cuarto, de alguna manera, resume los dos anteriores por cuanto repite las preposiciones de uno y otro ("a" y "por"). El quinto ("aterrar...") y el sexto ("ex- 
traer...") son sintáctica y rítmicamente simétricos (verbo transitivo, complemento circunstancial, complemento directo). Al final se distiende la tensión tanto por la brevedad del séptimo término como por la pausa que lo precede. En el quinto párrafo hay un descenso gradual hasta que el impulso o la voz se pierde en la distancia como el hablante de ese "tren nocturno", shaman que nos ha hipnotizado para desaparecer al fin.

Textos como éste llevaron a Cortázar a afirmar que "tenia la impresión de que se hubieran escrito a sí mismos" y que "participan de esa suspensión de la contingencia y de la incredulidad en las que Coleridge veía las notas privativas de la más alta operación poética'. ${ }^{11}$ En realidad, están plasmando los rasgos que Friedrich descubre en la lírica moderna, notablemente en Poe y Rimbaud:

Desde Novalis hasta Poe y Baudelaire, había ido madurando el procedimiento de hacer surgir un texto lírico no sólo partiendo de temas y motivos, sino también o quizás exclusivamente, por medio de combinaciones de las sonoridades del lenguaje y de las oscilantes asociaciones de ideas sugeridas por las palabras... Una poesía que ha dejado ya de tener en cuenta la inteligibilidad normal puede recurrir a este método con tanta mayor facilidad cuanto que en ella la palabra como sonoridad y sugestión es algo aparte de la palabra al servicio de un sentido lógico. En la palabra se desencadenan fuerzas alógicas que guian las expresiones y que, gracias a series sonoras insólitas, ejercen un encanto inusitado. ${ }^{12}$

El lenguaje deja de ser instrumento o vehículo de transmisión de imágenes o emociones y reclama atención por sí mismo. Casi de cualquier frase del texto puede decirse que existe no tanto para comunicar algo sino porque ha sido convocada por una frase anterior con la que comparte rasgos sonores afines. Sin tratar de comparar Historias de cronopios y de famas con las Illuminations, creo que puede seguirse con provecho el consejo de Friedrich al lector de Rimbaud: léase la secuencia en voz alta. Tal lectura demostrará que no hay nada que entender. Sólo hay que sentir la onda verbal y perderse en ella.

University of Florida, Gainesville

GRACIELA COULSON

11 "Del sentimiento de no estar en todo", en La vuelta al dia en ocbenta mundos (Madrid: Siglo XXI de España Editores, 1970), Tomo I, p. 41.

12 H. Friedrich, op. cit., pp. 141-142. Véase también: “..la poesía nace del impulso del lenguaje, el cual, por su parte, y obedeciendo a la 'nota' prelingüistica, señala el camino donde se encuentran los contenidos; éstos no son ya propiamente la sustancia dêl poema, sino que son portadores de las fuerzas musicales y de sus vibraciones más allá del significado... Esta clase de poesía se explica como una entrega a fuerzas mágicas del lenguaje”'(p. 75). 
